\title{
RANCANG BANGUN APLIKASI PENGHITUNGAN INVERS MATRIKS ORDO 3X3 DAN 4X4 DENGAN METODE INCREMENTAL PROCESS BERBASIS MULTIMEDIA
}

\author{
Sofida Kartika Ningrum \\ Teknik Informatika, Sekolah Tinggi Teknik PLN \\ Jakarta, Indonesia \\ Efy Yosrita \\ Teknik Informatika, Sekolah Tinggi Teknik PLN \\ Jakarta, Indonesia
}

\begin{abstract}
ABSTRAK
Metode invers matriks terdiri dari metode partisi matriks, adjoint matriks, dan operasi baris elementer. Dalam aplikasi pembelajaran invers matriks yang telah dibuat sebelumnya, hanya berisi satu metode invers matriks pada masing-masing aplikasi. Aplikasi yang sudah ada masih masih terpisah untuk setiap metodenya dikarena dibuat oleh orang yang berbeda. Ketika dipergunakanan dalam perkuliahan mata kuliah Aljabar Linear di temukan kendala dari aplikasi tersebut dimana aplikasi hanya dapat dijalankan pada perangkat komputer tertentu. Hal ini memotivasi penulis membuat aplikasi yang dapat dijalankan pada semua perangkat komputer dan menggabungkan pembahasan semua metode dalam satu aplikasi. Aplikasi berupa, simulasi yang disertai dengan materi, latihan, dan permainan untuk memudahkan mahasiswa dalam memahami materi mengenai invers matriks yang diberikan di kelas. Metode pengembangan perangkat lunak atau SDCL (System Development Life Cycle) yang digunakan dalam penelitian ini adalah metode Incremental Process Model, perancangan antarmuka dan pengkodean menggunakan software Microsoft Visual Studio 2010 Ultimate.
\end{abstract}

Kata Kunci : Aljabar Linear, Invers Matriks, Simulasi, Multimedia, SDLC, Incremental Process Model

\section{ABSTRACT}

Matrix inverse method consists of a method of partitioning a matrix, adjoint matrix, and elementary row operations. In the matrix inverse learning application that was created earlier, it was contains only one method of inverse matrix in each application. Existing application still separated for each method cause made by different people. When lecture used the application in courses of Linear Algebra, actualy the application can only run on a particular computer device. This was motivated writers to created applications that can run on all devices komputer and combines of all methods in a single application. Application form is accompanied by material simulations, exercises and games to enable students to understand the material of the inverse matrix given in class. Software development methods or SDCL (System Development Life Cycle) is the method Incremental Process Model, interface design and coding using Microsoft Visual Studio 2010 Ultimate.

Keyword : Linear Algebra, Inverse matrix, Simulation, Multimedia, SDLC, Incremental Process Model

\section{Pendahuluan}

Invers matriks merupakan salah satu materi pembelajaran dari mata kuliah Aljabar Linear. Dalam invers matriks ini terdapat beberapa macam metode, diantaranya adalah metode partisi matriks, adjoint matriks, dan operasi baris elementer. Pada penelitian sebelumnya telah di buat beberapa aplikasi untuk menghitung invers matriks, namun masing- masing aplikasi hanya memuat satu metode saja. Kendala dari aplikasi tersebut adalah aplikasi hanya dapat dijalankan pada perangkat komputer dengan sistem operasi Windows tipe 32 bit. Hai ini memotivasi penulis untuk mengembangkan aplikasi yang dapat dijalankan pada semua perangkat komputer yang memuat ketiga metode menghitung invers matrik dalam satu aplikasi serta menambahkan game dalam aplikasi tersebut, agar memotivasi bagi pengguna aplikasi untuk mencoba kemampuannya dalam menentukan invers matrik dalam format yang berbeda. Metode pengembangan perangkat lunak atau SDCL (System Development Life Cycle) yang digunakan dalam penelitian inii adalah metode Incremental Process Model, perancangan antarmuka dan pengkodean menggunakan software Microsoft Visual Studio 2010 Ultimate.

\section{Penelitian Terkait}

Berikut beberapa penelitian yang telah dilakukan terkait dengan pengembangan aplikasi simulasi :

a. Simulasi Menghitung Invers Matriks dengan Metode OBE (Operasi Baris Elementer) Menggunakan Microsoft Visual Basic 6.0, merupakan peneltian yang dilakukan oleh 
Agustian Asriyansyah. Dalam penelitian ini peneliti mengembangkan sebuah aplikasi untuk menghitung invers matrik dengan menggunakana metode Operasi Baris Elementer (OBE). Aplikasi ini bangun menggunakan bahasa pemrograman Microsoft Visual Basic 6.0.

b. Aplikasi Simulasi Menghitung Invers Matriks nxn dengan Menggunakan Metode Adjoint, merupakan penelitian yang di lakukan oleh Arif Budiman. Dalam penelitian ini peneliti mengembangakan sebuah aplikasi simulasi untuk menghitung invers matrik dengan menggunakan metode Adjoint. Aplikasi ini di bangun menggunakan bahasa pemrograman Visual Basic.Net

c. Aplikasi Simulasi Menghitung Determinan Matriks dengan Menggunakan Metode CROUT, merupakan penelitian yang dilakukan oleh Rizka Agustian. Dalam penelitian ini peneliti mengembangakan sebuah aplikasi simulasi untuk menghitung determinan matrik dengan menggunakan metode Crout. Aplikasi ini di bangun menggunakan bahasa pemrograman Visual Basic.Net

\section{Metodologi Penelitian}

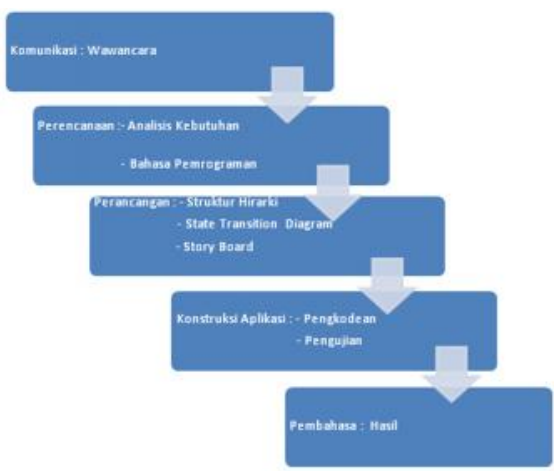

Gambar 1. Metodologi Penelitian

\subsection{Komunikasi}

Berdasarkan wawancara dengan dosen pengampu mata kuliah Aljabar linear dilakukan analisis sistem berjalan dan usulan. Berikut hasil analisisnya :

TABel 1. ANALISA Sistem BerJalan dan SISTEM USULAN

\begin{tabular}{|l|l|l|}
\hline No. & Sistem Berjalan & Sistem Usulan \\
\hline 1. & $\begin{array}{l}\text { Aplikasi Invers } \\
\text { Matriks terdiri dari } \\
\text { satu metode Invers } \\
\text { Matriks }\end{array}$ & $\begin{array}{l}\text { Aplikasi berisi metode- } \\
\text { metode invers matriks } \\
\text { yang terdiri dari } \\
\text { metode Partisi, } \\
\text { Adjoint, dan Operasi } \\
\text { Baris Elementer. }\end{array}$ \\
\hline & $\begin{array}{l}\text { Aplikasi berjalan pada } \\
\text { perangkat komputer } \\
\text { dengan sistem } \\
\text { operasi Windows tipe } \\
\text { 32 bit }\end{array}$ & $\begin{array}{l}\text { peranganan banda } \\
\text { dengan sistem operasi } \\
\text { Windows tipe 32 bit } \\
\text { dan 64 bit }\end{array}$ \\
\hline
\end{tabular}

\begin{tabular}{|l|l|l|}
\hline 3. & $\begin{array}{l}\text { Pada menu latihan, } \\
\text { diberikan soal secara } \\
\text { acak dan menjawab } \\
\text { pada kolom yang } \\
\text { tersedia. Setelah } \\
\text { jawaban dimasukkan, } \\
\text { maka akan } \\
\text { melakukan koreksi } \\
\text { dengan menampilkan } \\
\text { jawaban benar. }\end{array}$ & $\begin{array}{l}\text { Pada menu latihan, } \\
\text { diberikan soal secara } \\
\text { acak dan menjawab } \\
\text { pada kolom yang } \\
\text { tersedia. Setelah } \\
\text { jawaban dimasukkan, } \\
\text { maka akan melakukan } \\
\text { koreksi dengan } \\
\text { menampilkan jawaban } \\
\text { benar dan dapat } \\
\text { menampilkan langkah- } \\
\text { langkah perhitungan. }\end{array}$ \\
\hline 4 & $\begin{array}{l}\text { Pada menu latihan, } \\
\text { terdiri dari satu soal. }\end{array}$ & $\begin{array}{l}\text { Pada menu latihan, } \\
\text { terdiri dari 10 soal } \\
\text { dengan menampilkan } \\
\text { fitur penilaian yang } \\
\text { berupa skor dan } \\
\text { grade. }\end{array}$ \\
\hline 5. & $\begin{array}{l}\text { Fitur yang diberikan } \\
\text { terdiri dari materi, } \\
\text { simulasi, latihan, dan } \\
\text { game. }\end{array}$ \\
\hline & $\begin{array}{l}\text { Fitur yang diberikan } \\
\text { terdiri dari materi, }\end{array}$ \\
\hline simulasi, dan latihan.
\end{tabular}

\subsection{Perencanaan}

Suatu sistem aplikasi dapat berjalan baik apabila terdapat perencanaan di dalamnya dengan mendeskripsikan apa saja yang akan dilakukan dalam pembuatan suatu sistem aplikasi. Pada tahap ini meliputi analisis kebutuhan dan menentukan bahasa pemrograman yang digunakan.

\section{a. Analisis Kebutuhan}

Pada tahap awal penelitian, peneliti melakukan wawancara dengan dosen pengampu mata kuliah Aljabar Linear.Setelah melakukan komunikasi dengan dosen mengenai aplikasi yang diinginkan, tahap selanjutnya adalah melakukan analisis kebutuhan yang diperlukan dalam pembuatan aplikasi. Pada aplikasi sebelumnya, aplikasi hanya kompatibel dengan sistem operasi Windows 32 bit. Pada tahap ini penulis menganalisa perangkat lunak dan perangkat keras yang dibutuhkan agar aplikasi dapat berjalan baik di perangkat computer dengan sistem operasi Windows 32 bit dan 64 bit.

\section{b. Bahasa Pemrograman}

Pada tahap perencanaan ini, penulis menentukan untuk menggunakan bahasa pemrograman VB.Net.

\subsection{Perancangan}

Pada tahap ini, penulis melakukan perancangan yang diperlukan dalam pembuatan aplikasi yang meliputi :

a. Perancangan Struktur Hirarki

Berikut digambarkan struktur hirarki dari aplikasi penghitungan invers matriks : 


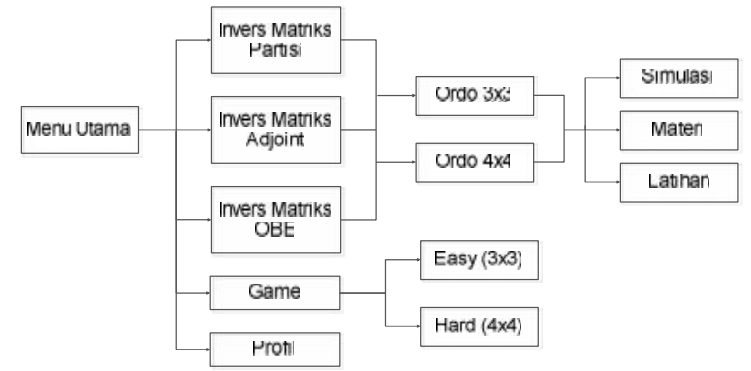

Gambar 2. StRUKTUR HIRARKI MENU UTAMA

Hirarki di atas menggambarkan struktur layar menu utama yang terdiri dari Menu Invers Matriks Partisi, Menu Invers Matriks Adjoint, Menu Invers Matriks OBE, Menu Game, dan Menu Profil.

b. Perancangan STD (State Transition Diagram)

State Transition Diagram adalah suatu diagram yang menggambarkan suatu proses dihubungkan satu sama lain dalam waktu yang bersamaan. State Transition Diagram digambarkan dengan sebuah state yang berupa komponen sistem yang menunjukkan bagaimana kejadiankejadian tersebut dari satu state ke state yang lain. Pada aplikasi sebelumnya, STD terdiri dari STD menu utama, materi, simulasi, ordo, dan latihan. Pada perancangan ini penulis menambahkan STD untuk menu game.

\section{- $\quad$ STD Menu Utama}

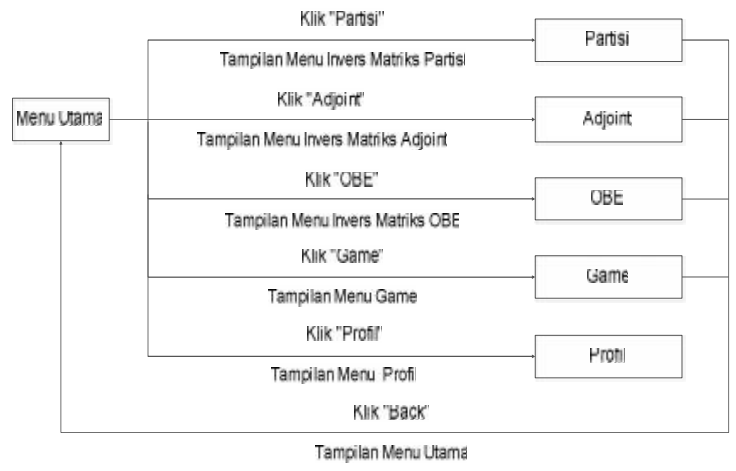

\section{GAMBAR 3 STD MENU UTAMA}

Pada aplikasi penghitungan invers matriks, menu yang pertama kali muncul adalah Menu Utama. Menu ini terdiri dari lima pilihan menu, diantaranya Menu Partisi, Menu Adjoint, Menu OBE, Menu Game, dan Menu Profil.

\section{- $\quad$ STD Menu Partisi / Adjoint / OBE}

Pada STD ini terdapat form untuk menampilkan pilihan ordo penghitungan invers matriks, yaitu ordo $3 \times 3$ dan $4 \times 4$ sesuai dengan metode invers matriks yang sedang dipilih.

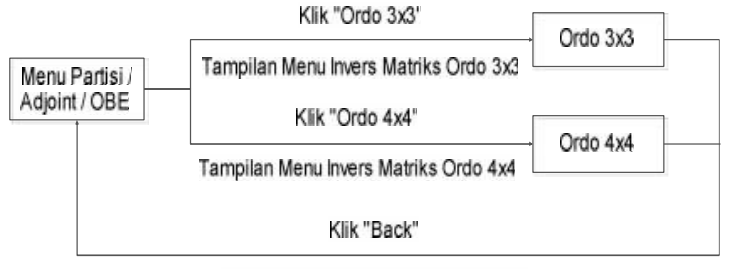

Tampilan Menu Partisi / Adjoint / OBE

Gambar 4. STD Menu PartisI / AdJoInt / OBE

\section{- $\quad$ STD Menu Ordo 3×3 / 4x4}

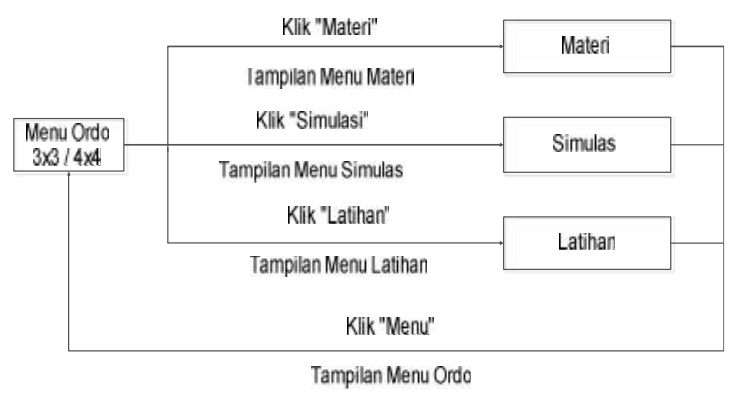

Gambar 5. STD Menu Ordo 3×3 / 4x4

Pada STD ini terdapat form untuk menampilkan tiga pilihan menu sesuai dengan ordo dan metode yang sudah dipilih, yaitu Menu Materi, Menu Simulasi dan Menu Latihan.

\section{- $\quad$ STD Menu Game}

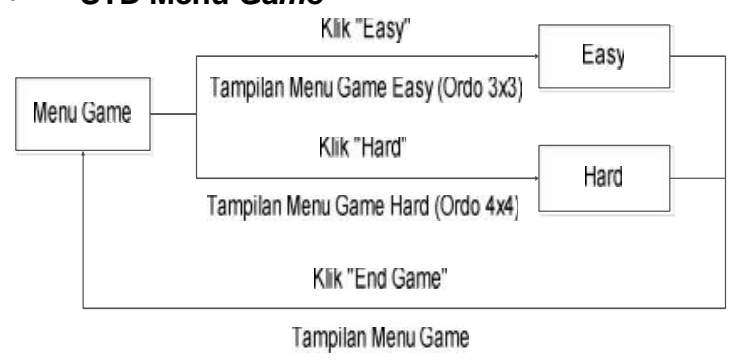

GambaR 6. STD MENU GAME

Pada STD Game ini terdapat form untuk menampilkan dua pilihan menu tingkatan permainan, yaitu Menu Easy dan Menu Hard.

\section{c. Perancangan Storyboard}

Dalam tahap ini dilakukan perancangan storyboard. Storyboard merupakan rangkaian gambar yang dibuat secara keseluruhan sehingga menggambarkan suatu cerita, dan gambaran dari cerita yang akan dibuat, maka harus mudah dimengerti oleh semua pihak. Perancangan storyboard ini meliputi perancangan halamanhalaman menu pada aplikasi ini, penentuan letak menu, header, footer, serta content dari aplikasi. Berikut story board untuk form pembuka aplikasi penghitungan invers matriks 


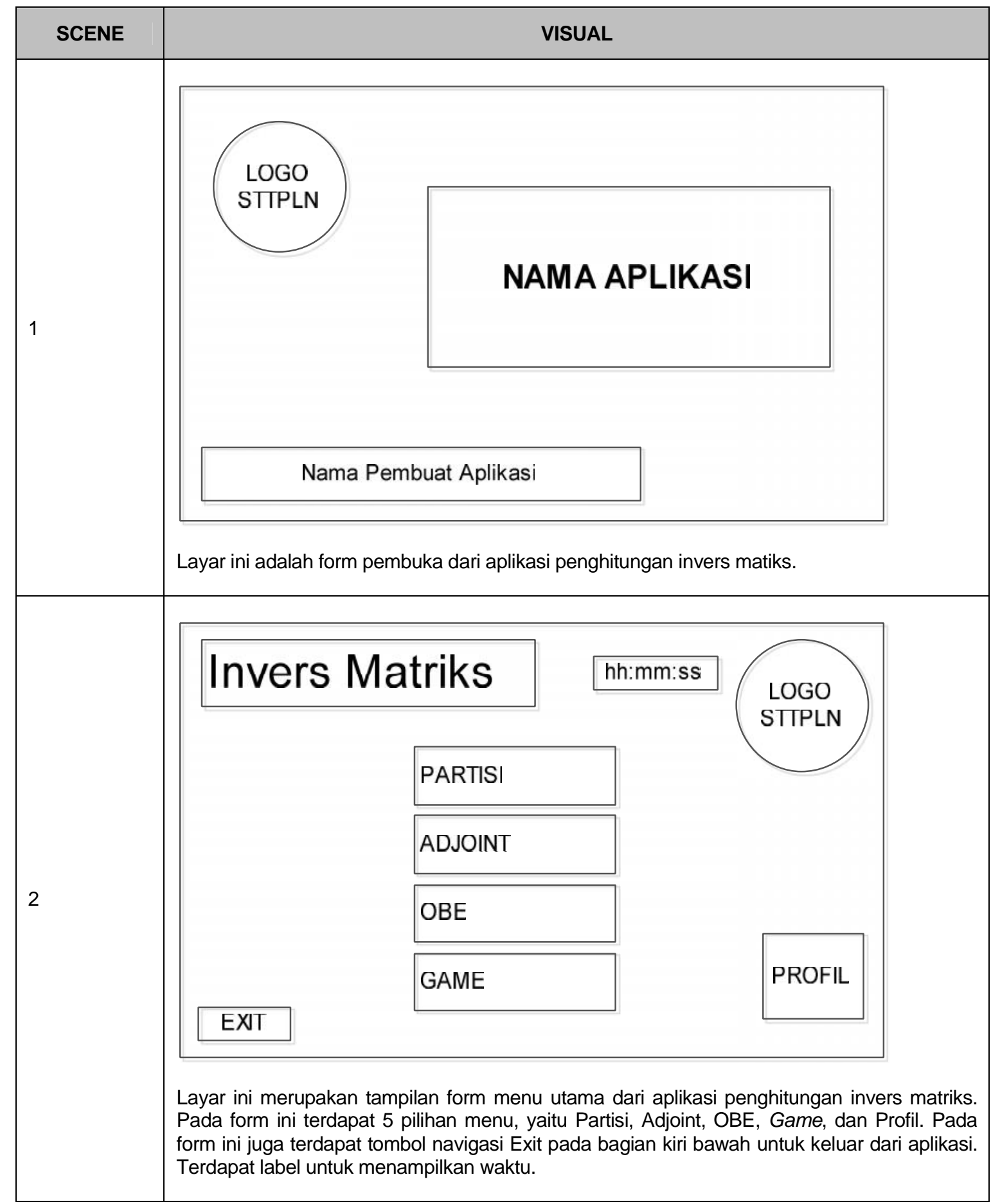

Gambar 7. Story Board Form Pembuka

\subsection{Konstruksi Aplikasi}

Pada tahap ini, penulis mulai melakukan pembuatan aplikasi pada Microsoft Visual Studio 2010 Ultimate, yang meliputi :

a. Pengkodean

Pada aplikasi sebelumnya, pembuatan antarmuka aplikasi berupa menu utama, menu ordo, menu simulasi, menu materi, dan menu latihan. Pada pengembangan aplikasi penulis menambahkan menu grade latihan dan menu game. Selain itu, penulis menghubungkan menu latihan dengan menu simulasi. Pada tahap ini, penulis melakukan pembuatan antarmuka aplikasi kemudian membuat pengkodean. Pengkodean bertujuan untuk menunjang aplikasi agar dapat berjalan dengan baik sesuai yang diharapkan.

\section{b. Pengujian}

Pengujian terhadap aplikasi dilakukan dengan melakukan pengujian blackbox untuk mengetahui kesesuaian aplikasi dengan kebutuhan. Jika aplikasi yang dibuat sesuai dengan yang 
diharapkan, maka aplikasi tidak memerlukan adanya perbaikan, tetapi jika tidak sesuai dengan yang diharapkan, maka akan dilakukan pengecekan kembali pada tahap pengkodean hingga dapat berjalan dengan baik. Selain itu, penulis melakukan pengujian terhadap beberapa perangkat komputer dengan sistem operasi Windows yang memiliki tipe sistem 32 bit dan 64 bit untuk mengetahui aplikasi dapat berjalan baik.

\subsection{Pembahasan}

Setelah dilakukan analisis, tahap terakhir penelitian ini adalah membahas hasil pelaksanaan penelitian, yang menjabarkan tentang tahapan tahapan pelaksanaan penelitian ini.

Berdasarkan perancangan sebelumnya, maka tahap yang dilakukan penulis selanjutnya adalah melakukan pembuatan aplikasi pada Microsoft Visual Studio 2010 Ultimate. Penulis melakukan pembuatan antarmuka aplikasi kemudian membuat pengkodean. Adapun hasil perancangan aplikasi invers matriks ini adalah sebagai berikut.

- Tampilan Opening Aplikasi

Pada gambar di bawah ini merupakan tampilan opening dengan menampilkan animasi pada saat aplikasi pertama kali dijalankan.

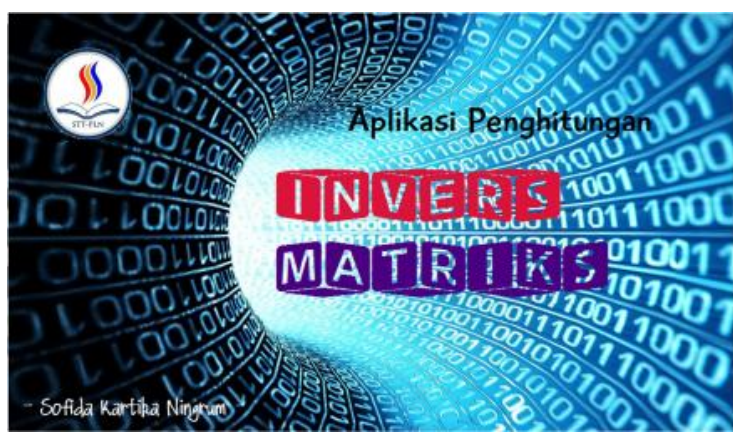

Gambar 8. Tampilan Opening Aplikasi

- $\quad$ Tampilan Menu Utama

Halaman awal dari aplikasi penghitungan invers matriks setelah tampilan opening menampilkan menu-menu utama. Menu utama terdiri dari menu Partisi, Adjoint, OBE, Game, dan Profil. Menu-menu tersebut berisi pilihan metode penghitungan invers matriks, permainan, dan profil seputar aplikasi yang dapat dipilih sesuai yang diinginkan.

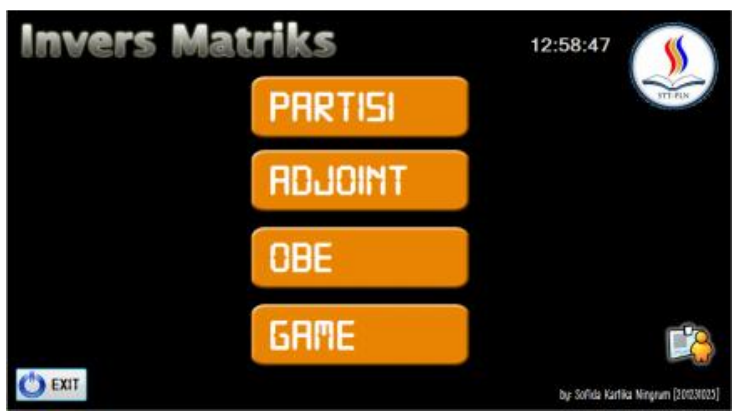

Gambar 9. Tampilan Menu Utama
- Tampilan Menu Materi

Halaman menu materi merupakan halaman yang menampilkan materi pembelajaran invers matriks dalam bentuk pdf. Materi ini dikelompokkan berdasarkan metode penyelesaian dan jumlah ordo pada penghitungan invers matriks.

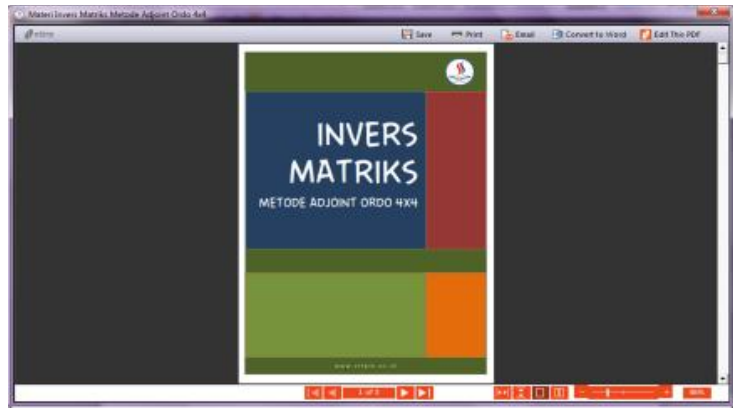

Gambar 10. Tampilan Menu Materi

- Tampilan Menu Simulasi

Halaman menu simulasi merupakan halaman yang menampilkan simulasi perhitungan invers matriks secara langkah demi langkah. Simulasi dibedakan menjadi dua ordo, yaitu $3 \times 3$ dan $4 \times 4$ sesuai dengan metode penghitungan invers matriks. Di bawah ini merupakan tampilan simulasi dengan ordo $3 \times 3$.

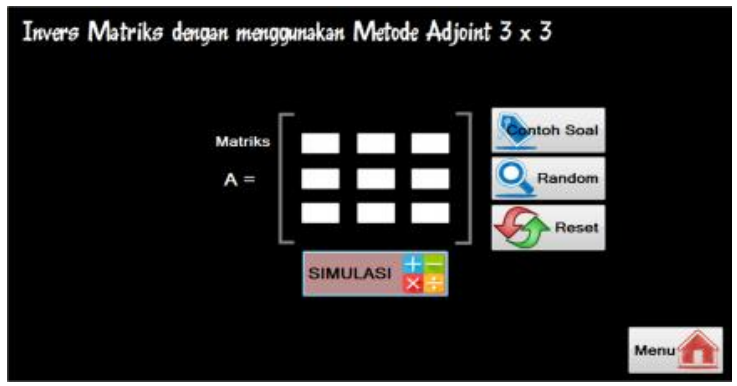

Gambar 11. Tampilan Menu Simulasi Ordo 3×3

\section{- Tampilan Menu Latihan}

Halaman menu latihan merupakan halaman yang menyediakan soal-soal untuk berlatih menyelesaikan penghitungan invers matriks. Latihan terdiri dari ordo $3 \times 3$ dan $4 \times 4$. Soal yang diberikan bersifat acak. Pengguna mengerjakan soal latihan pada halaman ini untuk mengasah kemampuan dan memperdalam pemahaman mengenai invers matriks.

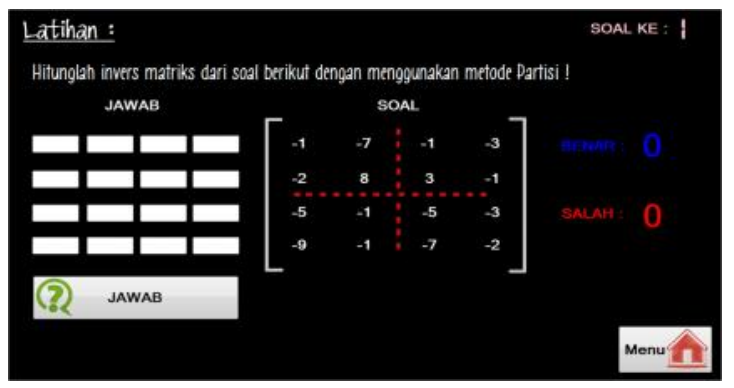

Gambar 12. Tampilan Menu Latihan 
- $\quad$ Tampilan Menu Game

Halaman menu game menyediakan permainan dalam menghitung invers matriks. Game yang diberikan pada aplikasi ini terdiri dari Level Easy (ordo $3 \times 3$ ) dan Hard (ordo $4 \times 4$ ). Pada Game ini peserta mengerjakan beberapa soal mengenai invers matriks. Soal yang diberikan bersifat acak.

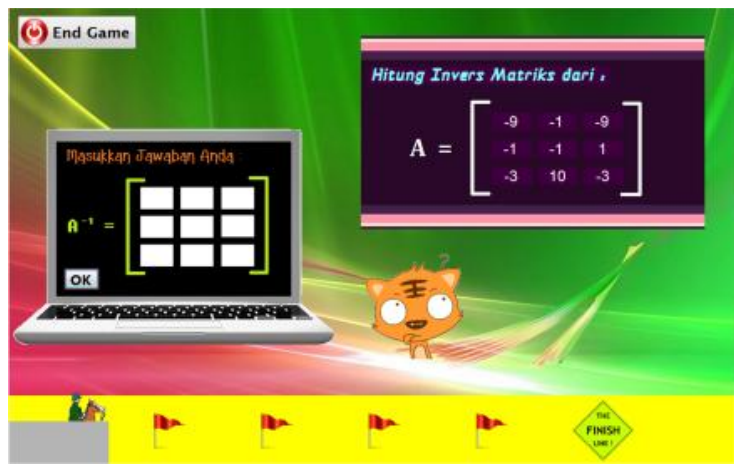

Gambar 13. Tampilan Menu Game

Aplikasi ini dikembangkan untuk menyempurnakan aplikasi-aplikasi sejenis yang sudah ada, diantaranya aplikasi simulasi untuk menghitung invers matrik dengan menggunakan metode partisi, aplikasi simulasi untuk menghitung invers matrik dengan menggunakan metode Adjoint dan aplikasi simulasi untuk menghitung invers matrik dengan menggunakan metode Operasi baris elementer (OBE). Ketiga aplikasi tersebut kemudian dikonsep ulang, dengan menggabungkan ketiganya dalam sebuah aplikasi dengan ditambahkan game sebagai media belajar yang lebih menyenangkan. Aplikasi dirancang berbasis multimedia agar membantu mahasiswa dalam memahami penghitungan invers matriks. Aplikasi invers matriks terdiri dari menu materi, simulasi, latihan, dan game yang dibuat dengan tujuan mudah digunakan oleh pengguna (user-friendly), karena menu-menu yang ditampilkan sangat jelas dan mudah sekali dipahami.

Pengujian pada aplikasi dilakukan penulis dengan menggunakan metode Black box dan pengujian terhadap berbagai perangkat komputer diantaranya personal komputer (PC) dan Laptop, dengan sistem operasi Windows 32 bita dan 64 bit. Pada pengujian tersebut aplikasi sudah berjalan dengan baik. Selain itu, penulis melakukan wawancara kepada dosen mata kuliah Aljabar Linear yang disertai dengan demo aplikasi. Berdasarkan hasil pengumpulan data, didapatkan bahwa aplikasi cukup sesuai dengan keinginan pengguna.

Dalam menyelesaikan pembuatan aplikasi ini tentunya penulis menemui beberapa kendala. Misalnya kesulitan dalam membuat langkahlangkah perhitungan pada simulasi dikarenakan langkahnya yang panjang. Kemudian penulis mengalami kesulitan pada saat membuat konsep game agar animasi dapat berjalan dengan baik. Dari sistem baru yang diusulkan, ditemukan kelebihan dan kekurangan aplikasi. Adapun kelebihannya antara lain :
1. Metode-metode Invers Matriks terorganisir ke dalam satu aplikasi.

2. Aplikasi dapat dijalankan pada perangkat komputer PC dan Laptop dengan sistem operasi Windows baik 32 bit maupun 64 bit.

3. Menu pada latihan soal memiliki fitur penilaian yang dapat menguji kemampuan diri terhadap penghitungan invers matriks.

4. Terdapat fitur Game untuk menciptakan suasana yang lebih menyenangkan terhadap penghitungan invers matriks. Game ini dibagi menjadi 2 level yaitu easy untuk matrik ordo $3 \times 3$ dan hard $4 \times 4$

Sedangkan untuk kekurangan dari aplikasi invers matriks ini, diantaranya:

1. Aplikasi hanya memuat metode penyelesaian dengan ordo $3 \times 3$ dan $4 \times 4$.

2. Belum adanya fitur cetak simulasi yang berfungsi menyimpan langkah-langkah perhitungan invers matriks.

\section{Kesimpulan dan Saran}

Dari hasil penelitian yang dilakukan dari tahap awal hingga proses konstruksi aplikasi, dapat disimpulkan bahwa :

1. Aplikasi penghitungan invers matriks memiliki fitur materi, simulasi, latihan, dan game dengan batasan ordo $3 \times 3$ dan $4 \times 4$. Langkahlangkah perhitungan pada simulasi sesuai dengan materi yang diajarkan.

2. Aplikasi penghitungan invers matriks dirancang dengan menggunakan Microsoft Visual Studio 2010 Ultimate yang dapat memberikan alternatif bagi mahasiswa belajar materi invers matriks pada mata kuliah Aljabar Linear.

3. Aplikasi penghitungan invers matriks dapat dijalankan di berbagai perangkat komputer dengan sistem operasi Windows, baik pada tipe sistem 32 bit maupun 64 bit.

4. Berdasarkan hasil dan pembahasan, aplikasi penghitungan invers matriks mudah untuk digunakan (user-friendly).

\section{DAFTAR PUSTAKA}

Agustian, R. (2013). Aplikasi Simulasi Menghitung Determinan Matriks dengan Menggunakan Metode CROUT. Jakarta : Sekolah Tinggi Teknik PLN.

Asriyansyah, A. (2012). Simulasi Menghitung Invers Matriks dengan Metode OBE (Operasi Baris Elementer) Menggunakan Microsoft Visual Basic 6.0. Jakarta: Sekolah Tinggi Teknik PLN.

Binanto, I. (2010). Multimedia Digital Dasar Teori + Pengembangan. Yogyakarta: ANDI.

Budiman, A. (2013). Aplikasi Simulasi Menghitung Invers Matriks nxn dengan Menggunakan Metode Adjoint. Jakarta: Sekolah Tinggi Teknik PLN.

K.Sibero, A. F. (2010). Dasar-Dasar Visual Basic.net. Jakarta: MediaKom.

Leon, S. J. (2001). Aljabar Linear Dan Aplikasinya (Edisi 5). Jakarta: Erlangga. 
Noviyansyah. (2012). Aplikasi Simulasi Penghitung Invers Matriks Ordo nxn Menggunakan Metode OBE. Jakarta: Sekolah Tinggi Teknik PLN.

Pressman, R. S. (2010). Rekayasa Perangkat Lunak. Yogyakarta: AND.

Pribadi, M. A. (2013). Perancangan Aplikasi simulasi Penyelesaian Sistem Persamaan Linier dengan Metode Eliminasi Gauss Jordan. Jakarta: Sekolah Tinggi Teknik PLN.
Santoso, I. (2009). Interaksi Manusia dan Komputer (Edisi 2). Yogyakarta: ANDI.

Sutojo, T. (2010). Teori Dan Aplikasi Aljabar Linier \& Matriks Dengan Implementasi Aljabar Linier \& Matriks Menggunakan Matlab. Yogyakarta: ANDI. 